\title{
Development of a Concept Inventory for Introductory Environmental Engi- neering Courses
}

\author{
Dr. Sukalyan Sengupta, University of Massachusetts, Dartmouth \\ Prof. Jeffrey A Cunningham, University of South Florida
}

Dr Jeffrey Cunningham is an Associate Professor in the Department of Civil and Environmental Engineering at the University of South Florida (USF). Dr Cunningham's research and teaching interests are related to the fate, transport, and remediation of contaminants in the environment. His current students are working on projects related to the clean-up of soil contaminated by hazardous chemicals, the fate of trace organic contaminants during reclamation of treated municipal wastewater, and the storage of carbon dioxide in deep saline aquifers as a method of mitigating global climate change. Several previous research projects focused on the transport and biodegradation of hazardous chemicals in groundwater. Dr Cunningham regularly teaches an introductory Environmental Engineering class for undergraduate Civil Engineering students, as well as graduate classes on physical and chemical processes in natural and engineered environmental systems. Dr Cunningham earned his BS degree in Chemical Engineering from Rice University, his MS degree in Civil Engineering from Stanford University, and his PhD in Civil \& Environmental Engineering from Stanford University. He has authored or co-authored nearly thirty papers in peer-reviewed scientific journals. When not at work, he enjoys spending time with his family and watching baseball.

\section{Dr. Sarina J. Ergas, University of South Florida}

Dr. Ergas is a professor and graduate program coordinator in the Department of Civil \& Environmental Engineering at the University of South Florida. She received a BS in Environmental Engineering from Humboldt State University and MS and PhD degrees from the University of California, Davis. Her research focuses on environmental biotechnology, including wastewater treatment and bioremediation. She was a 2007 Fulbright Fellow at the Technion Israel Institute of Technology and a 1995 ASCE Excellence in Civil Engineering Education (ExCEEd) Fellow. She teaches classes in Biological Principles, Air Pollution Control and Environmental/Water Resources Capstone Design. Dr. Ergas is a registered professional engineer in the Commonwealth of Massachusetts.

\author{
Dr. Ramesh K. Goel, University of Utah \\ Dilek Ozalp, University of South Florida \\ Dr. Teri Reed-Rhoads, Purdue University, West Lafayette
}




\section{Development of a Concept Inventory for Introductory Environmental Engineering Courses}

Introduction and Objectives

Fundamentals of Environmental Engineering (FEE) is a core component of undergraduate curricula in civil engineering, environmental engineering, environmental resources engineering, and public health, and is increasingly becoming a core course in other disciplines, such as chemical engineering, mechanical engineering, and sustainability studies. FEE is often a foundation (pre-requisite) course for electives such as water treatment, wastewater treatment, air pollution control, hazardous waste treatment, and solid waste management. These electives are critical to the nation since they provide the academic background needed for the national publichealth infrastructure. Furthermore, FEE is becoming increasingly important as the United States makes a major thrust toward renewable energy and away from a fossil-fuel-based economy.

Conceptual understanding is an important pedagogical goal in FEE instruction, or, indeed, in engineering instruction. The celebrated book How People Learn ${ }^{1}$ heavily emphasizes the importance of conceptual understanding. The authors assert that students who organize facts and ideas within a conceptual framework are more likely to learn new information quickly and will also be able to apply what they have learned to new situations. However, there are currently no validated and reliable instruments for assessing students' comprehension of core concepts in FEE classes. This lack results in at least two important challenges for FEE instructors. First, there is no quantitative way to assess whether different teaching approaches, such as laboratory projects, different classroom formats or curricular ordering, improve students' conceptual understanding of FEE material. Second, it may be difficult for instructors to determine which fundamental, underlying concepts give students the most difficulty and prevent them from mastering course material at the desired level.

A strategy that has been used to address this problem in other fields is the development and implementation of a Concept Inventory. A Concept Inventory (CI) test is an assessment tool that has proven to be effective in identifying misconceptions of concepts. The pioneering work in CI development was the Force Concept Inventory (FCI), a brainchild of David Hestenes and coworkers $^{2,3}$ at Arizona State University. CIs are typically multiple-choice tests that incorporate visual diagrams and everyday situations to emphasize conceptual understanding over mathematical manipulation. They include carefully crafted incorrect answers that encompass many common student misconceptions. The CI model has been applied by educators in many engineering disciplines and today CIs exist for chemistry ${ }^{4}$, biology ${ }^{5}$, statistics $^{6-9}$, electromagnetics ${ }^{10}$, electromagnetic waves ${ }^{11-12}$, circuits $^{13}$, signals and systems ${ }^{14}$, strength of materials $^{15}$, thermodynamics ${ }^{16}$, materials science ${ }^{17}$, dynamics ${ }^{18-19}$, fluid mechanics ${ }^{20-21}$, and statics $^{22}$. 
Therefore, the objectives of this project are to: (1) develop a Fundamentals of Environmental Engineering Concept Inventory (FEECI) that quantifies students' conceptual understanding of key FEE concepts, (2) administer the FEECI at 10 US universities with required undergraduate FEE courses, and (3) refine and disseminate the FEECI following its initial administration. The expected outcome of this work is a validated, reliable instrument for assessing conceptual understanding in a core curriculum course for Civil and/or Environmental engineering. Such an instrument will play an important role in assessment for programmatic accreditation under the ABET standards, and provide a needed technique for formative assessment of instructional methods and pedagogical frameworks in the FEE curriculum. Another important outcome will be the formation of a FEECI Development Team, a strong community of faculty, trained in the use of the FEECI and dedicated to improving FEE instruction.

\section{Procedure}

The planned approach to achieve the objectives of this project is as follows.

1. Form an FEECI Development Team - a group of faculty members from 10 universities who have taught FEE courses for multiple years;

2. Conduct an online Delphi study of the FEECI Development Team to identify concepts in FEE courses that are critical but prone to misconception among students;

3. Conduct student interviews and brainstorming sessions to generate a list similar to that developed in stage \# 2;

4. Reconcile the lists obtained from stages $2 \& 3$ to identify the key concepts to be included in the FEECI;

5. Generate the multiple-choice FEECI questions, including the "stems" (questions or prompts), the correct answers, and distractors (incorrect answers) based on common student misconceptions;

6. Administer a "beta version" FEECI to students at 10 campuses in Fall 2013;

7. Conduct statistical analysis of validity and reliability of the FEECI using data from the 10 campuses;

8. Refine the FEECI questions (including both stems and distractors) based on analysis of test data, student interviews, and expert peer review;

9. Prepare documentation describing the use of the FEECI and guiding the interpretation of the results;

10. Disseminate the FEECI through work with the collaborative Development Team, conference and journal publications, workshops, and a website that will be linked to the ciHUB, an online community of concept inventory developers, users, and researchers.

At the time this paper is being written, stages $1-4$ have been completed, stage 5 is in progress, and stage 6 is being planned. 
Summary of Completed Work

Stage 1. The FEECI Development Team consists of professors from the following universities: University of Massachusetts at Dartmouth (lead institution), University of South Florida (co-lead institution), University of Utah (co-lead institution), Florida State University, Humboldt State University, Lehigh University, Missouri University of Science \& Technology, Northeastern University, University of Colorado at Denver, and Utah State University. Development team faculty submitted their syllabi and the following topics were selected based on a review of the syllabi: mass balances, environmental chemistry, environmental biology, risk assessment, and environmental measurements and units.

Stage 2. Each member of the FEECI Development Team completed an on-line survey as the first step of the Delphi study. The on-line survey asked members of the Development Team to identify up to five key concepts within each of topics listed above. For each concept listed, the Development Team member also indicated his/her opinion or perception of how important that concept is, and how difficult it is for students, using a five-point Likert scale for each. The member also indicated his/her rationale for including that particular concept in the list.

The five topics (mass balances, environmental chemistry, environmental biology, risk assessment, and environmental measurements and units) were selected because they were identified as common to all (or nearly all) FEE courses at the participating universities. In contrast, topics such as water treatment, wastewater treatment, or air pollution are sometimes omitted from FEE courses and taught as separate upper-level electives. However, many of the concepts that challenge students in topics such as water treatment or wastewater treatment would also fall under the heading of one (or more) of the five topics identified here. For instance, "Monod growth kinetics" or "biochemical oxygen demand" are both concepts that are applicable to the topic of wastewater treatment, but here would likely be listed under the topic of environmental biology.

It should be noted that identification of concepts by the Development Team members was "openended." In other words, members were not, for instance, prompted to select a concept from a menu. Instead, members were able to phrase their responses in any manner desired. Because of this, some interpretation of members' responses is required to determine if two members have identified the same concept. For instance, if one member wrote "oxygen demand," one wrote "BOD," and one wrote "biochemical oxygen demand," these were all considered to be the same concept. In most (but not all) cases, it was fairly clear if two responses corresponded to the same concept or to different concepts.

Responses of Development Team members were analyzed to identify the concepts that were most commonly indicated, how important each concept is, and how difficult each concept is. For instance, Figure 1 shows the concepts most frequently indicated within the topic of mass balances, along with the assessment of importance and difficulty. In the interest of space, results for the other four topics are not shown here. 


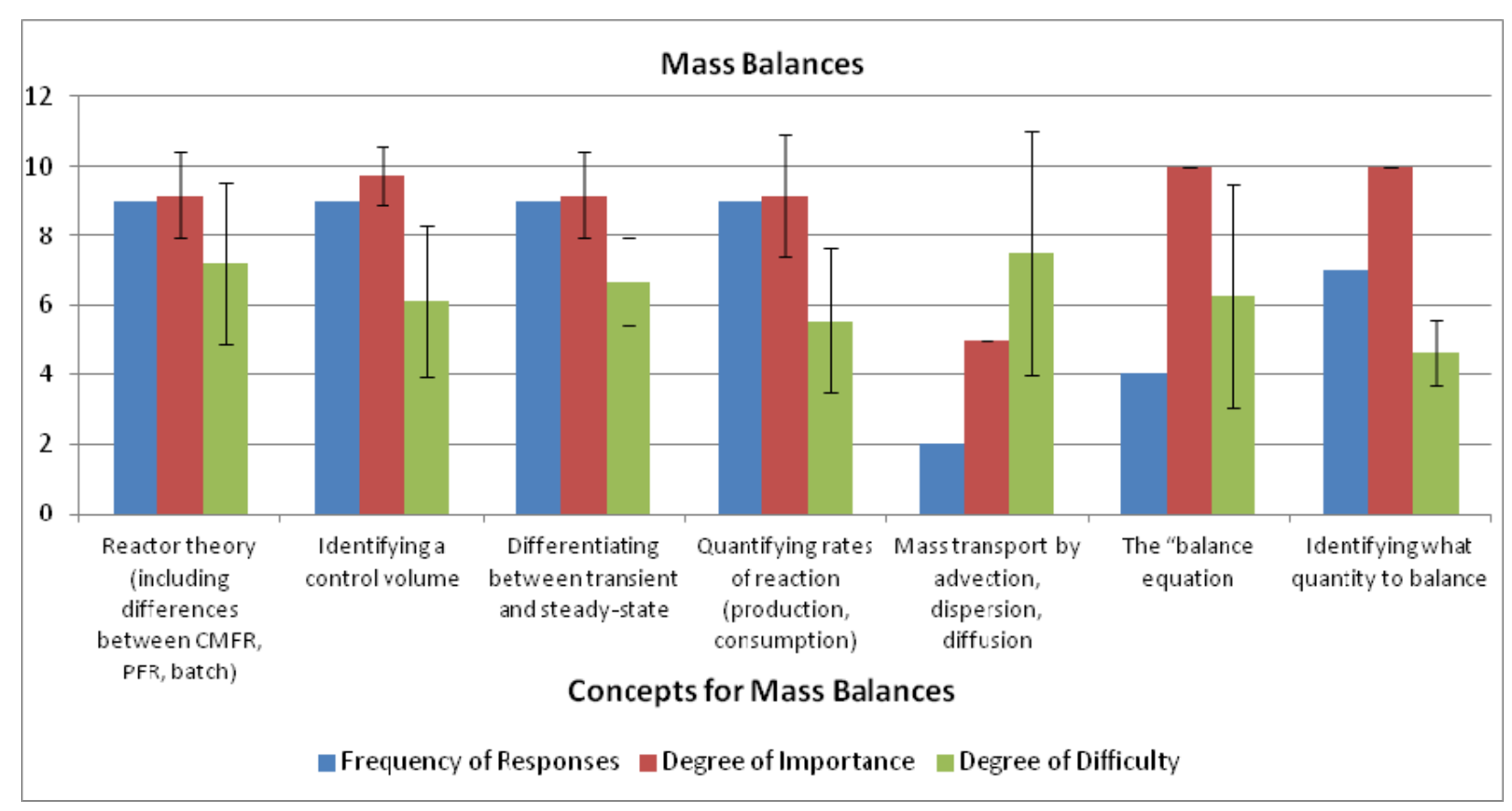

Figure 1: Most frequently indicated concepts for the topic of mass balances

Following identification of the most commonly indicated concepts for each topic, members of the Development Team were re-surveyed as the second round of the Delphi Study. In the second round, members were given the results of the first round, and then asked again to rate the importance and the difficulty of each concept. The rationale of the Delphi method is that it iteratively moves the team of experts towards a consensus on which concepts are most important and difficult.

Stage 3. Simultaneously with the second round of the Delphi study, 10 students were surveyed at each of three universities: University of Massachusetts at Dartmouth, University of South Florida, and University of Utah. The thirty students were volunteers from a pool of students who had recently completed a FEE course. Similarly to the second-round Delphi study of the Development Team, students were given the results of the first-round Delphi study and were asked to rate the importance and the difficulty of each concept.

Stage 4. Following the second-round Delphi study and the student surveys, data were analyzed to identify those concepts that were considered most important and most difficult by both faculty and students. There is a practical limit to the number of concepts that can be covered on the eventual FEECI test; the test is expected to consist of approximately thirty questions, and each concept to be included on the FEECI test must be represented by multiple questions, so it may be possible to include only 4-8 concepts on the test. Analysis of the Delphi study data and the student survey data identified eight concepts as most important and most difficult: (1) the mass 
balance equation; (2) chemical equilibrium; (3) partitioning; (4) biochemical oxygen demand; (5) reactor theory; (6) reaction kinetics; (7) definition of risk; and (8) unit conversions.

\section{Work Currently in Progress}

Currently, we are working on formulating questions for each of the eight concepts identified above, for possible inclusion in the FEECI test. Questions consist of a "stem" (i.e., the prompt or question to be answered) along with a set of "distractors" (incorrect answers that represent common student misconceptions). To develop the distractors, we first develop the stems, and then administer those stems to student volunteers in an open-ended or "free response" fashion, i.e., without any choices for selection. Student volunteers are asked to describe (either verbally or in writing) their rationale or thought process for each question that they answer. If multiple student volunteers indicate a particular misconception or incorrect approach, that can be used to formulate a distractor for the multiple-choice version of the FEECI test.

For four of the eight concepts (mass balance equation, biochemical oxygen demand, reactor theory, and unit conversions), stems have been written and administered to students, and we are now in the process of writing the distractors for each question. An example is shown below. Figure 2 shows an example stem (for the reactor theory concept) that was administered to several students at one of the participating universities. Figure 3 shows scanned copies of two students' responses to the stem. Figure 4 shows what the question may eventually look like with stem and distractors present along with the correct answer.

A stream of water enters an ideal plug flow reactor. The volume of the reactor is $100 \mathrm{~L}$ and the volumetric flow rate is $50 \mathrm{~L} / \mathrm{hr}$. The influent (water entering the reactor) contains a contaminant. The influent concentration of the contaminant varies over time as shown in the figure below:

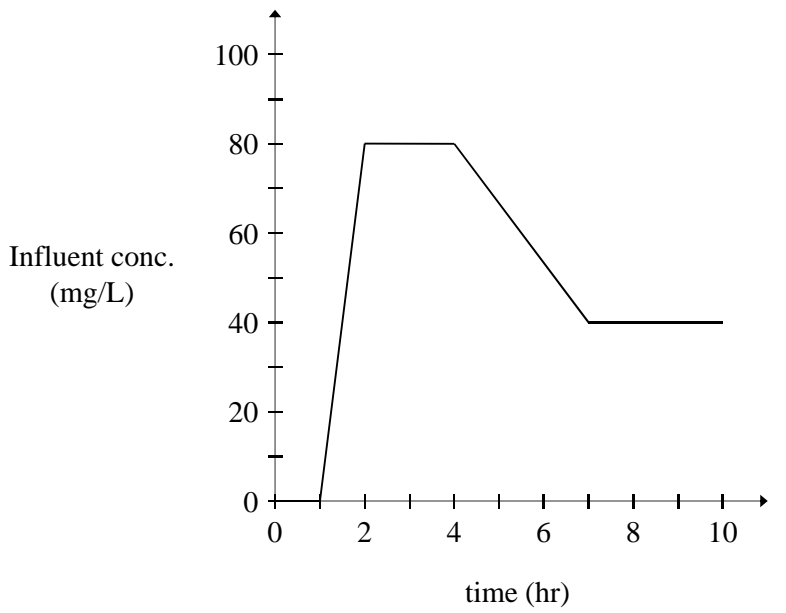

Assume that the contaminant is non-reactive. Draw a graph that shows the exiting concentration of contaminant as a function of time. Label your axes.

Figure 2: Example stem for a reactor theory question 
EXITING CONCENTRATION

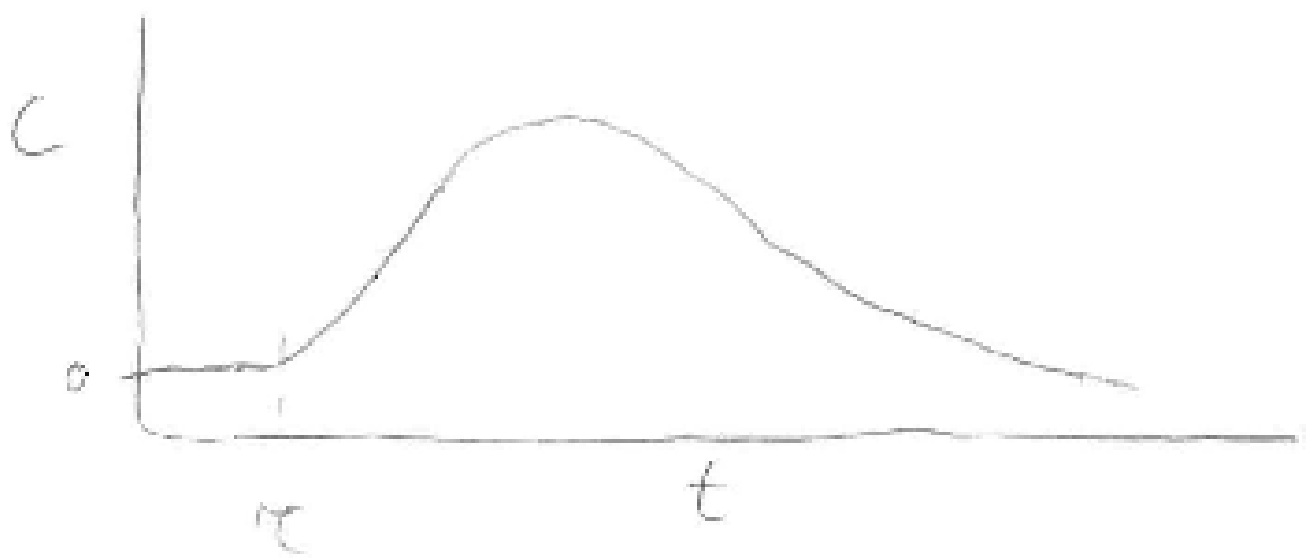

$$
\begin{aligned}
& \text { exitist } \\
& \text { cone } \\
& \text { (role })
\end{aligned}
$$
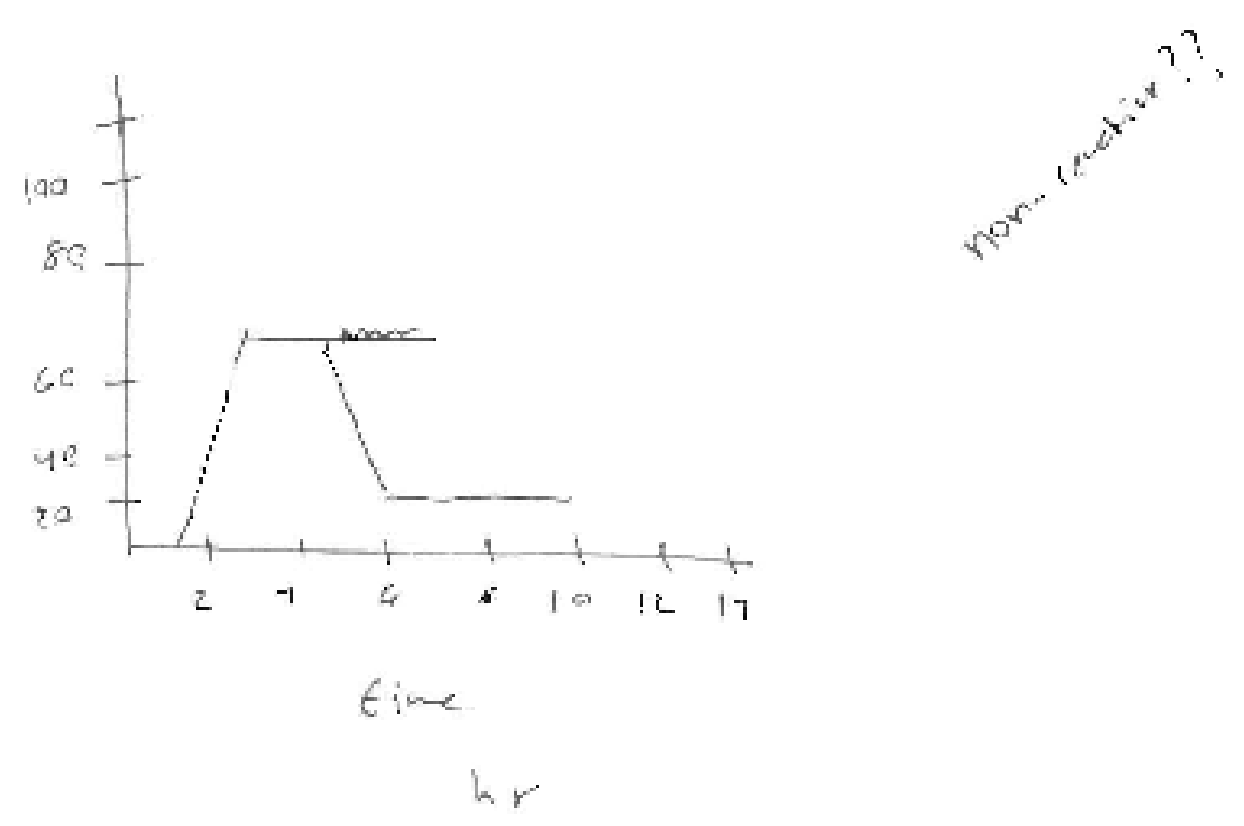

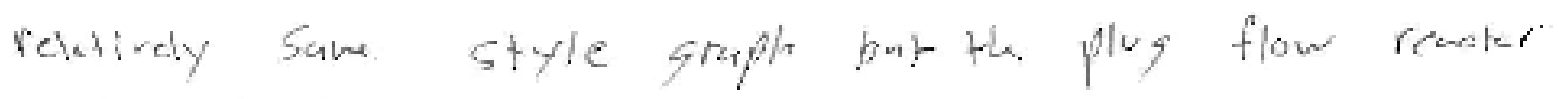
should treat some of the contarimat.

Figure 3: Scanned copies of two student answers to reactor theory question

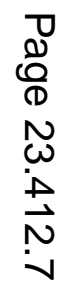


A stream of water enters an ideal plug flow reactor. The volume of the reactor is $100 \mathrm{~L}$ and the volumetric flow rate is 50 $\mathrm{L} / \mathrm{hr}$. The influent (water entering the reactor) contains a contaminant. The influent concentration of the contaminant varies over time as shown in the figure below:

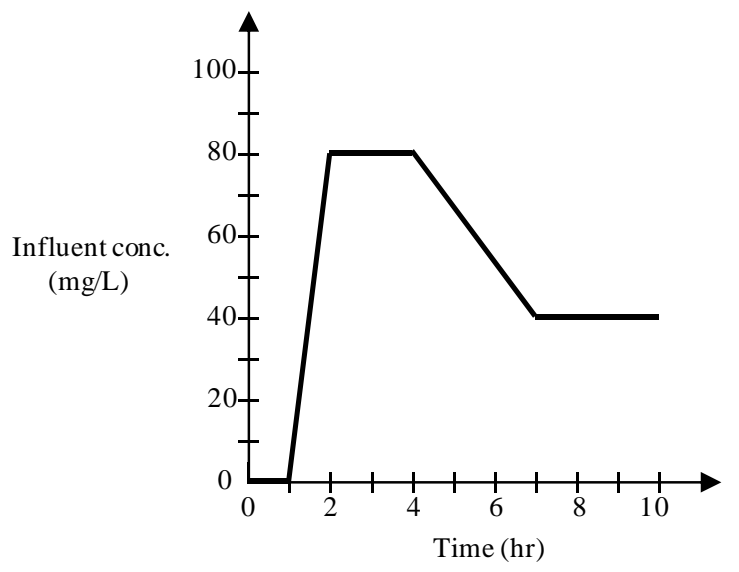

Assume that the contaminant is non-reactive. Which graph shows the exiting concentration of contaminant as a function of time?
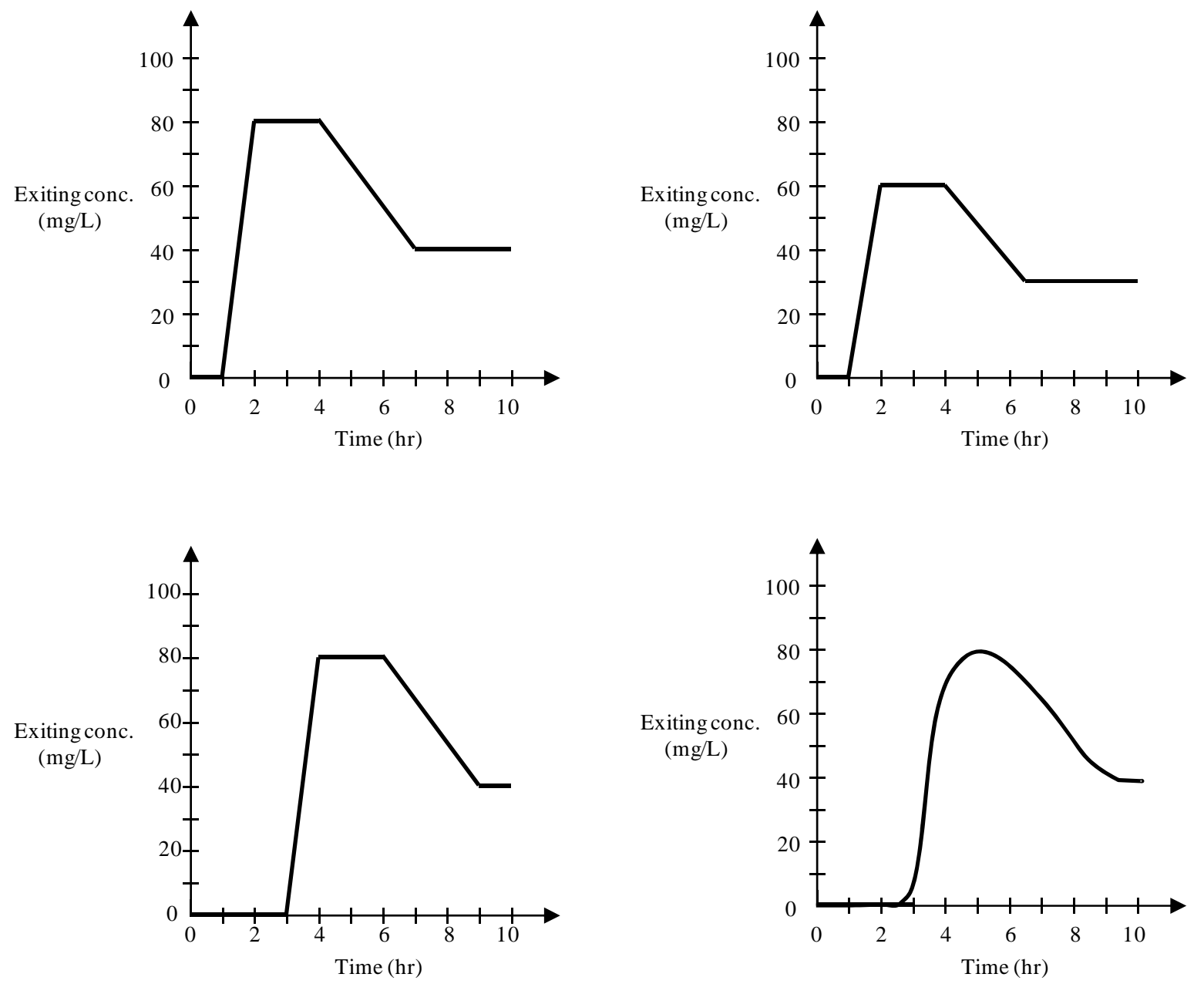

Figure 4: Example FEECI test question with stem, correct answer, and distractors 
The distractors in Figure 4 were based on incorrect answers provided by the students, two of which are shown in Figure 3. Inclusion of these distractors on the FEECI test will enable instructors to determine if students in FEE classes have the same misconceptions as those exhibited by the student volunteers.

\section{Next Steps}

At the time this paper is being written, we are in the process of formulating the distractors for the questions related to the four concepts that have already been administered to student volunteers (reactor theory, mass balance equation, biochemical oxygen demand, and unit conversions). Simultaneously, we are preparing stems for the remaining four concepts (chemical equilibrium, partitioning, reaction kinetics, definition of risk), and those stems will then be administered to student volunteers. It is anticipated that a "beta version" of the FEECI test will be available to administer to students in FEE courses during fall semester 2013 (stage 6). Following statistical analysis of the student results from the beta version (stage 7), the FEECI stems and distractors will be revised (stage 8) based on analysis of test data, student interviews, and expert peer review.

Bibliographic Information

1 Bransford JD, Brown AL, \& Cocking RR, 2000. How People Learn: Brain, Mind, Experience, and School (expanded edition). Washington, DC: National Academy Press.

2 Hestenes D, Wells M, \& Swackhamer G, 1992. Force concept inventory. The Physics Teacher, 30: 141-158.

3 Hestenes D \& Wells M, 1992. A mechanics baseline test. The Physics Teacher, 30: 159-166.

4 Krause S, Birk J, Bauer R, Jenkins B, \& Pavelich MJ, 2004. Development, testing, and application of a chemistry concept inventory. ASEE/IEEE 34th Annual Frontiers in Education Conference, Savannah, GA. doi: 10.1109/FIE.2004.1408473

5 Klymkowsky MW, Underwood SM, Garvin-Doxas RK, 2010. Biological Concepts Instrument (BCI): A diagnostic tool for revealing student thinking. Available at: http://bioliteracy.colorado.edu (accessed 10 January 2012).

6 Stone A, Allen K, Reed-Rhoads T, Murphy TJ, Shehab RL, \& Saha C, 2003. The Statistics Concept Inventory: A pilot study. ASEE/IEEE 33rd Annual Frontiers in Education Conference, Boulder, CO. doi: 10.1109/FIE.2003.1263336

7 Allen K, Stone A, Reed-Rhoads T, \& Murphy TJ, 2004. The Statistics Concepts Inventory: Developing a valid and reliable instrument. Proceedings of the 2004 American Society for Engineering Education Annual Conference \& Exposition, Salt Lake City, UT. Available at: http://www.asee.org/search/proceedings (accessed 10 January 2012).

8 Allen K, 2006. The Statistics Concept Inventory: Development and analysis of a cognitive assessment instrument in statistics. Doctoral dissertation, University of Oklahoma, Norman, OK.

9 Stone A, 2006. A psychometric analysis of the Statistics Concept Inventory. Doctoral dissertation, University of Oklahoma, Norman, OK. 
10 Notaros BM, 2002. Concept inventory assessment instruments for electromagnetic education. IEEE Antennas and Propagation Society, International Symposium, San Antonio, TX. doi: 10.1109/ APS.2002.1016436

11 Roedel RJ, El-Ghazaly S, Reed-Rhoads T, \& El-Sharawy E, 1998. The Wave Concepts Inventory - An assessment tool for courses in electromagnetic engineering. ASEE/IEEE 28th Annual Frontiers in Education Conference. doi: 10.1109/FIE.1998.738761

12 Reed-Rhoads T \& Roedel R, 1999. The Wave Concept Inventory - A cognitive instrument based on Bloom's Taxonomy. ASEE/IEEE 29th Annual Frontiers in Education Conference, San Juan, PR. doi: 10.1109/ FIE.1999.840416

13 Herman GL, Loui MC, Zilles C, 2011. Students' misconceptions about medium-scale integrated circuits. IEEE Transactions on Education, 54(4): 637-645. doi: 10.1109/TE.2011.2104361

14 Wage KE \& Buck JR, 2001. Development of the Signals and Systems Concept Inventory (SSCI) assessment instrument. ASEE/IEEE 31st Annual Frontiers in Education Conference, Reno, NV. doi: 10.1109/ FIE.2001.963690

15 Richardson J, Steif P, Morgan J, \& Dantzler J, 2003. Development of a concept inventory for strength of materials. ASEE/IEEE 33rd Annual Frontiers in Education Conference, Boulder, CO. doi: 10.1109/ FIE.2003.1263342

16 Midkiff KC, Litzinger TA, \& Evans DL, 2001. Development of engineering thermodynamics concept inventory instruments. ASEE/IEEE 31st Annual Frontiers in Education Conference, Reno, NV. doi: 10.1109/FIE.2001.963691

17 Krause S, Decker JC, \& Griffin R, 2003. Using a materials concept inventory to assess conceptual gain in introductory materials engineering courses. ASEE/IEEE 33rd Annual Frontiers in Education Conference, Boulder, CO. doi: 10.1109/FIE.2003.1263337

18 Gray GL, Evans D, Cornwell P, Costanzo F, \& Self B, 2003. Toward a nationwide Dynamics Concept Inventory assessment test. Proceedings of the 2003 American Society for Engineering Education Annual Conference \& Exposition, Nashville, TN. Available at: http://www.asee.org/search/proceedings (accessed 10 January 2012).

19 Gray GL, Costanzo F, Evans D, Cornwell P, Self B, Lane JL, 2005. The Dynamics Concept Inventory assessment test: A progress report and some results. Proceedings of the 2005 American Society for Engineering Education Annual Conference \& Exposition, Portland, OR. Available at: http://www.asee.org/ search/proceedings (accessed 10 January 2012).

20 Martin JK, Mitchell J, \& Newell T, 2003. Development of a concept inventory for fluid mechanics. ASEE/IEEE 33rd Annual Frontiers in Education Conference, Boulder, CO. doi: 10.1109/FIE.2003.1263340

21 Martin JK, Mitchell J, \& Newell T, 2004. Work in progress: Analysis of reliability of the Fluid Mechanics Concept Inventory. ASEE/IEEE 34th Annual Frontiers in Education Conference, Savannah, GA. doi: 10.1109/FIE.2004.1408578

22 Steif PS \& Dantzler J, 2005. A Statics Concept Inventory: Development and psychometric analysis. Journal of Engineering Education, 33: 363-371. 